\title{
Therapeutic Nuclear Medicine in the UK
}

\author{
John Buscombe
}

\subsection{Introduction}

Therapeutic Nuclear Medicine in the United Kingdom has developed in a fairly inconsistent way over the last 50 years. It is a sad inditement of the state of British nuclear medicine that access to good therapeutic nuclear medicine has become little more than a "post code lottery" [1]. This in part has been due to the uneven spread of specialists in nuclear medicine with most posts being concentrated in the South East and North West. It is not therefore surprising that most therapeutic nuclear medicine has developed in these areas as well. Diagnostic nuclear medicine was traditionally performed by nuclear medicine physicians and radiologists but the latter have generally showed little interest in radionuclide therapy as it was not seen as "radiology". An alternate source of expertise lies with clinical oncology and in many parts of the U.K radionuclide therapy is delivered by clinical oncologists. However, as oncologists have taken a system based approach to treatment and those who are licenced to treat thyroid cancer may have little interest in cancers in other sites. Compounded to this has been decision by clinical oncologists to withdraw from treatment of benign disease. Some endocrinologists have taken on the role of treating benign thyroid disease but of course they will not do radiation synevectomies. The delivery of radionuclide therapy also requires further craft group skills in particular trained clinical scientists, technologists, radiopharmacy and nursing. All this has led to a centripetal effect with expertise being concentrated in less than ten centres across the UK. The majority of these centres lie within Greater London further exacerbating the poor geographic distribution of services. The biggest change over the past 5 years which may be temporary change in funding with

\footnotetext{
J. Buscombe

Department of Nuclear Medicine, Cambridge University Hospitals,

Cambridge CB2 0QQ, UK 
central funding in England for radium-223, peptide radionuclide radiotherapy (PRRT) and to a lesser extent yttrium-90 particulates for selective intra-arterial radio-therapy (SIRT) for metastasis in the liver. For those centres who already offer a range of radionuclide therapies adding these newer treatments has some resource implications but does not normally require extensive business planning to get approval to start treatments. Therefore even with new funding patients have tended to be seen and treated in those centres who have already undertaken a range of radionuclide therapies.

\subsection{Radioiodine}

The greatest success story for radionuclide therapy has been the use of I-131 for both benign and malignant thyroidal disease [2]. Since the first treatments 70 years ago in Manchester most patients in the United Kingdom have access to I-131 and the specialist clinics that have been developed for assessing the need for treatment and follow-up. In benign thyroid disease it has been shown that early treatment with I-131 is cost effective and preferable to years of trials of anti-thyroid medication. It is considered routine (Fig. 16.1) but once was a revolution, quoting the great Ralston Paterson from Manchester "The first point to be emphasised is that this use of radioiodine in thyroid cancer represents a completely new principle of therapy-the principle of systemic ingestion with, thereafter, selective absorption of a drug carrying

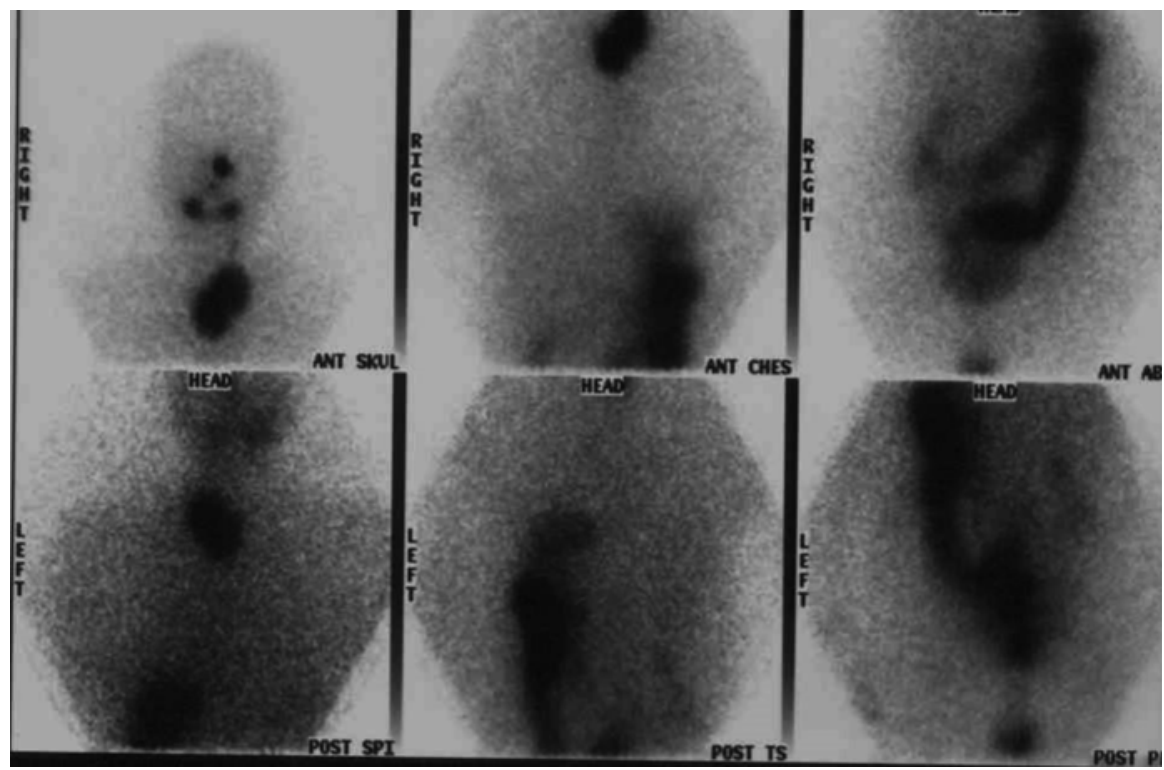

Fig. 16.1 A series of spot gamma camera images from the 1980s showing residual uptake in the neck and physiological activity in the large bowel 
a radioactive element in it and resulting in a zone of localised high radiation dosage in the selective absorption tissues".

Once thought too dangerous to give to young women it would now be considered ideal especially if they were considering having children. In thyroid cancer, there has been a rare British triumph with the recent "HiLo" trial showing that for those with low risk cancers ablation with $1.1 \mathrm{GBq}$ is as good as using $3.7 \mathrm{GBq}$ [3]. This has resulted in a reduction in the risk of radioiodine associated morbidity and of much greater interest to the managers of the National Health Service a reduced number of days in a hospital bed.

\subsection{Relieving Bone Pain}

The second theme in radionuclide therapy was the relief of bone pain. Initially this depended on the use of phosphorus-32 a bone seeking radiopharmaceutical. However, its long half-life resulted in a high level of bone marrow suppression. The next strategy was to administer a radiopharmaceutical to an area of limited disease and thus radiation synovectomy was developed with an emphasis of Y-90 colloids injected into inflamed knees. A technique which consistently delivers pain relief in $80 \%$ of patients to whom it is administered with relief of pain lasting 12 months or more. However, the number of practitioners who regularly give this safe and inexpensive treatments are so rare that when the author had a private practice in Harley Street, good business was had by flying patients over from New York for treatment.

Then came another British story. There remained great need for a radionuclide that could treat the pain from bone metastases but not have the side effects of P-32. Looking down the periodic table below calcium lies strontium and $\mathrm{Sr}-89$ could deliver a soft beta with a short path length but still a long half-life. This product was developed by the newly privatised Amersham International with Prof Duncan Ackery from Southampton [4], his clinical scientist Dr Glenn Blake and two registrars Sandy McEwan and Val Lewington. The science was great as $70 \%$ of patients had good or complete pain relief, the marketing was abysmal. The American Merrell-Dow company developed a Samarium diphosphonate (Sm-153 EDTMP) as a sort of strontium "light" with a shorter half-life it could be used in those with higher disease burdens [5]. This was the first radionuclide therapy in which a full phase III clinical trial was performed but after looking like it would be a success interest also fizzled out after a decade.

The latest incarnation is another group-2 element Radium-223 which has been jointly developed by Bayer and the Norwegian company Algeta. After a clinical trial of 1000 patients (the largest contributing country being the UK) it was shown that 6 cycles of Ra-223 not only reduced the pain from bone metastases of prostate cancer but patients lived longer [6]. Therefore with Ra-223 patients liver better and liver longer. So far Ra-223 looks to be successful but time will tell. 


\subsection{Theranostics}

Though the term theranostics is relatively recent, nuclear medicine has been performing theranostics since the first radioiodine scan. The meaning of the word theranostics is not clearly defined but is generally understood to mean combining relevant diagnostic and therapeutic methods. This is ideally suited to nuclear medicine and the first designed theranostic agent was first used in the United Kingdom in 1986 by the Southampton group using low activity I-131 meta-iodo benzyl guinadine (MIBG) and then high activity I-131 MIBG to treat malignant phaeochromocytomas [7] and later its use was expanded into other tumour types such as carcinoid [8] and more importantly neuroblastoma with much work being done at University College Hospital London (UCHL) by Drs Jamshed Bomanji and Dr Mark Gaze.

The most successful form of theranostics however, has been the use of somatostatin analogues for the treatment of neuroendocrine tumours. This method was first proposed by Prof Eric Krenning in Rotterdam [9] but using various methods has become more widely used in the United Kingdom with many centres using the optimised imaging of Ga-68 DOTATATE PET and Lu-177 DOTATATE therapy. Though not licenced products these agents hold European Medicine Agency orphan drug status. Also presently those patients being treated for disseminated neuroendocrine tumours which are resistant to chemotherapy or biologicals can have the radioactive treatment funded centrally within England. Using this approach it looks as though 70-80\% of patients have a good palliative outcome with a low rate (1-4\%) of significant long lasting toxicity [10].

However not all theranostic agents have proved to be so accepted Y-90 tostisuomab is an antibody that can be used to treat CD20 expressing non-Hodgkins lymphomas (NHL). However, despite clear evidence that a single treatment can be as effective as several months of biologicals [11] it has failed to be used widely and must be considered a commercial failure. The reasons for this failure is unclear but it had to compete with other non-radioactive agents supported by large pharmaceutical companies with large advertising budgets.

It seems that theranostic radionuclide therapy will only be allowed to be successful where it does not threaten the commercial interest of large organisations but in reality this still gives us many rarer tumours, which often have unique targets, which we can aim to treat.

\subsection{The Double-Whammy}

The basis of most radionuclide therapy has been the systemic administration of a product that will use a molecular target such as a somatostatin receptor and this was the principle laid out by Paterson in 1950. However, what if the target disease is limited to one organ, would it not be possible to direct a treatment to that one organ and maximise the radioactivity delivered and reduce the radioactive dose to other tissues. Since the earliest days of nuclear medicine there have been attempts to do this for example giving I-131 lipiodol into the leg lymphatics of a patient with 

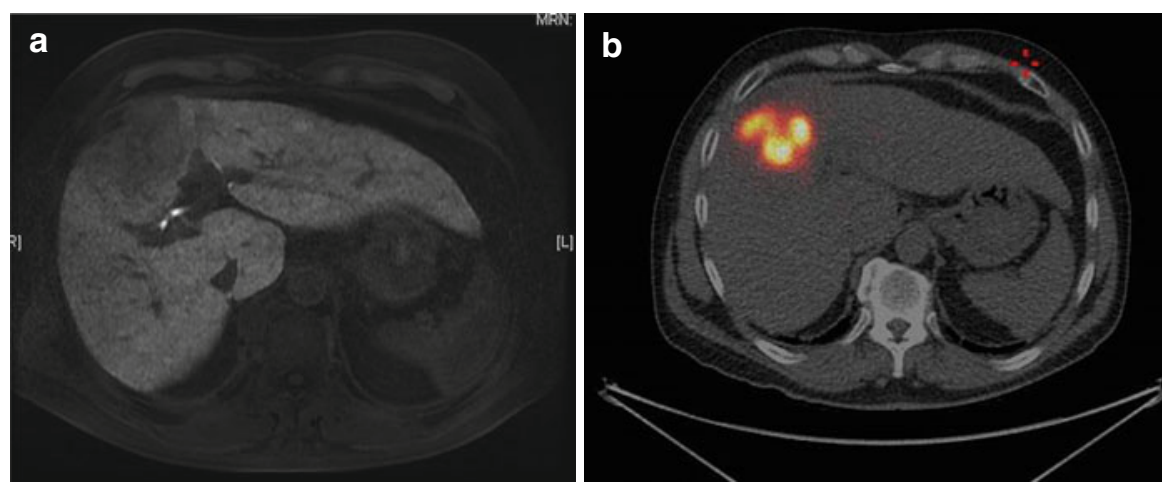

Fig.16.2 (a) A LAVA MR sequence showing a large primary HCC in segment 4. (b) A Y-90 Time of flight PET showing precise delivery of Y-90 resin particulates into segment 4 and localisation in the tumour delivering over 150 Gy tumour dose with minimal radiation to the rest of the liver

lymphoma or instilling Y-90 into the peritoneal cavity [12, 13]. The breakthrough came with the advances of a different technology; that of fast low dose fluoroscopy and interventional catheter design.

The liver would be a good target, there is no doubt that primary and secondary tumours in the liver are unlikely to be result in a long and happy life. The liver has a twin arterial blood supply but uniquely primary and secondary liver tumours are fed by the hepatic artery but normal hepatocytes also has an additional blood supply via the portal vein. A catheter placed in the relevant hepatic artery will deliver a radioactive substance which may have a radiation and an embolic effect so the tumour gets a "double whammy".

This idea was first used in a reasonable number of patients in Rennes in France using I-131 Lipiodol in primary hepatocellular cancer and brought to the UK by Dr Andrew Hilson at the Royal Free Hospital where it was shown to be as effective as chemotherapy loaded lipiodol but with fewer side effects [14, 15].

The next major steps took place in Canada with Y-90 labelled glass beads (Theraspheres) and in Australia Y-90 labelled resin beads (SIRspheres). In Clinical trials the use of these products in patients with metastases from colon cancer has been shown to improve survival [16]. Their use in the UK was pioneered in London by Prof Al-Nahhas at the Hammersmith Hospital and Dr Buxton-Thomas in Kings College Hospital. Presently their use is funded in 12 sites around England for evaluation by the radiotherapy clinical reference group in metastatic colo-rectal cancer but probably their greatest potential use to save lives is with hepatocelluar cancer (Fig. 16.2) but it is in this disease these treatments remain unfunded by the National Health Service.

\subsection{Dosimetry}

One area of deficiency in radionuclide therapy has been in the field of dosimetry. With external beam radiotherapy the distribution of radioactivity is highly predictable. This is not the case with systemic radionuclide therapy. Post therapy imaging is needed to 
look for the biodistribution of agents. However, an inherent problem is that molecular agents may not distribute homogeneously within a target tissue and these subtle changes may not be picked up by a technique which has a resolution of $1-2 \mathrm{~cm}$. In addition there are no agreed methodologies for calculating radiation doses or even what doses to calculate. It may be fairly easy to measure the whole body radioactivity every day in a patient who has received I-131 but how does that translate to a radiation dose to the salivary glands or even the target tumour?

If dosimetry is to be done and it is a legal requirement it is done there should be consensus on how dosimetry is done and what methods are used. In health systems that are becoming increasing short of resources it is vital that the radionuclide therapy community identify what personnel and training is needed to deliver dosimetry of high quality to all sites using these treatments [1].

\subsection{The Future}

When the BNMS celebrates its 75th anniversary will there be a chapter on radionuclide therapy? This is difficult to know. Many of us passionately believe in these methods but we have to accept that even in the nuclear medicine community we are a minority.

The recent appointment of Val Lewington as the UK's first professor of Nuclear Medicine with a special interest in radionuclide therapy must be a step in the right direction, however there is much to do. Radionuclide therapy is integral to the nuclear medicine curriculum but how many trainees really get to be immersed in therapy-still too few I fear.

As we enter into the age of personalized medicine theranostics and radionuclide therapy should become more important not less. This however, will need investment on a scale not seen before and a cadre of trained and enthusiastic nuclear medicine practitioners from all craft groups.

Open Access This chapter is distributed under the terms of the Creative Commons AttributionNoncommercial 2.5 License (http://creativecommons.org/licenses/by-nc/2.5/) which permits any noncommercial use, distribution, and reproduction in any medium, provided the original author(s) and source are credited.

The images or other third party material in this chapter are included in the work's Creative Commons license, unless indicated otherwise in the credit line; if such material is not included in the work's Creative Commons license and the respective action is not permitted by statutory regulation, users will need to obtain permission from the license holder to duplicate, adapt or reproduce the material.

\section{References}

1. Flux G, Moss L, Buscombe J, Gaze M, Guy M, Mather S, Orchard K. Molecular radiotherapy in the UK. London: British Institute of Radiology; 2011.

2. Paterson R. The treatment of thyroid carcinoma with radioiodine. Br J Radiol. 1950;23:553-6. 
3. Mallick U, Harmer C, Yap B, et al. Ablation with low dose radioiodine and thyrotropin alfa in thyroid cancer. N Engl J Med. 2012;366:1674-85.

4. Lewington VJ, McEwan AJ, Ackery DM, et al. A prospective randomised double blind crossover study to examine the efficacy of strontium- 89 in pain palliation in patients with advanced prostate cancer metastatic to bone. Eur J Cancer. 1991;27:954-8.

5. Serafini AN, Houston SJ, Resche I, et al. Palliation of pain associated with metastatic bone pain using samarium-153 lexidronam: a double blind placebo controlled clinical trial. J Clin Oncol. 1998;16:1574-81.

6. Parker C, Nilsson S, Heinrich D, et al. Alpha emitter radium-223 and survival in metastatic prostate cancer. N Engl J Med. 2013;369:213-23.

7. McEwan AJ, Shapiro B, Sisson JC, Beierwaltes WH, Ackery DM. Radio-iodobenzylguanadine for the scintigraphic location and therapy of adrenergic tumours. Semin Nucl Med. 1985;15:132-5.

8. Prvulovich EM, Stein RC, Bomanji JB, Ledermann JA, Taylor I, Ell PJ. Iodine-131 MIBG therapy of a patient with carcinoid liver metastases. J Nucl Med. 1998;39:1743-5.

9. Krenning EP, Kooij PP, Bakker WH, et al. Radiotherapy with a radiolabeled somatostain analogue [111In-DTPA-D-Phe1]-octreotide. A case history. Ann N Y Acad Sci. 1994;733:496-506.

10. Buscombe J, Navalkissoor S. Molecualr radiotherapy. Clin Med. 2012;12:381-6.

11. Witzig TE, Molina A, Gordon LI, et al. Long term responses in patients with recurring or refractory B cell non-Hodgkin lymphoma treated with yttrium-90 ibritumomab tiuxetan. Cancer. 2007;109;1804-10.

12. Hiniakowa I, Skalska-Vorbrodt J. Intralymphatic treatment of various neoplasms with radioisotope I-131. Clinical considerations. Pol Przegl Radiol Med Nukl. 1971;35:83-90.

13. Heneghan JB, Crook JN, Cohn I. Yttrium-90 microspheres for inhibition of intra-peritoneal tumor growth. Surg Forum. 1968;19:78-80.

14. Bretagne JF, Raul JL, Bourguet P, et al. Hepatic artery injection of I-131 labelled lipiodol. Part II. Preliminary results of therapeutic use in patients with hepatocellular carcinoma and liver metastases. Radiology. 1988;162:547-50.

15. Bhattacharya S, Novell JR, Dusciko GM, Hison AJ, Dick R, Hobbs KE. Epirubacin-Lipiodol chemotherapy versus 131- iodine-Lipiodol in the treatment of unresectable hepatocellular cancer. Cancer. 1995;76:2202-10.

16. Gray B, Van Hazel G, Hope M, Burton M, Moroz P, Anderson J, Gebski V. Randomised trial of SIR-spheres plus chemotherapy vs chemotherapy alone for treating patients with liver metastases from primary bowel cancer. Ann Oncol. 2001;12:1711-20. 


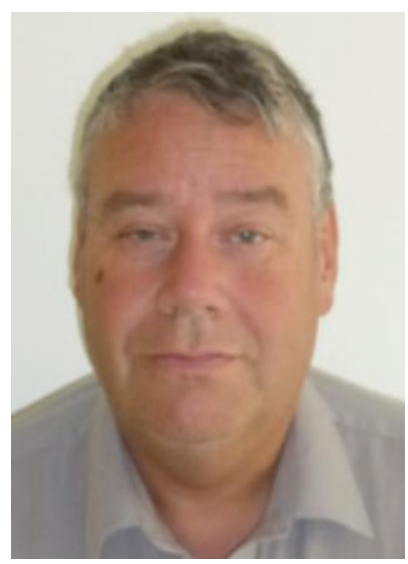

John Buscombe I trained in general internal medicine in London and Essex before being trained in Nuclear Medicine at the Middlesex Hospital, London.

My first Consultant post was at the Royal Free Hospital in London, I developed one of Europe's busiest therapeutic nuclear medicine practices. This included the development of directly injectable radiopharmaceuticals into arteries supplying brain and liver tumours. During this time, I was involved in a range of research projects including Phase I and II trials in both diagnostic and therapeutic nuclear medicine and also acted as principal investigator in international Phase III trials. These trials included the use of $99 \mathrm{mTc}$ MIBI in identifying and risk stratifying breast cancer and agents for imaging lung cancer and pulmonary emboli as well as the use of radioimmunotherapy for colon cancer and Hodgkin's lymphoma.

Since 2010 I have been working at Cambridge University Hospitals with a particular emphasis in cyclotron-based PET. The focus of these projects has been on the use of C-11 products in identifying sub-centimetre endocrine tumours and also PET imaging of atheroma and cardiovascular inflammation. I am also a Professor of Nuclear Medicine in the University of Pretoria developing nuclear medicine and education in an African setting

I have published over 200 papers in peer-reviewed journals, written or edited s7 books and written over 40 book chapters. I continue to work for the nuclear medicine community in the UK and Europe and have been a Council Member for the British Nuclear Medicine Society twice and has also served on the British Nuclear Medicine Society annual meeting scientific committee for a total of 6 years. 